\title{
Mould Growth Models and Risk Assessment for Emerging Timber Envelopes in Australia: A Comparative Study
}

\author{
Arianna Brambilla * and Eugenia Gasparri
}

check for updates

Citation: Brambilla, A.; Gasparri, E. Mould Growth Models and Risk Assessment for Emerging Timber Envelopes in Australia: A Comparative Study. Buildings 2021, 11, 261. https://doi.org/10.3390/ buildings11060261

Academic Editor: Sergej Medved

Received: 29 April 2021

Accepted: 16 June 2021

Published: 18 June 2021

Publisher's Note: MDPI stays neutra with regard to jurisdictional claims in published maps and institutional affiliations.

Copyright: (c) 2021 by the authors. Licensee MDPI, Basel, Switzerland. This article is an open access article distributed under the terms and conditions of the Creative Commons Attribution (CC BY) license (https:// creativecommons.org/licenses/by/ $4.0 /)$.
School of Architecture, Design and Planning, The University of Sydney, Sydney 2006, Australia; eugenia.gasparri@sydney.edu.au

* Correspondence: arianna.brambilla@sydney.edu.au

\begin{abstract}
Timber envelopes provide multiple benefits in reducing both operational and embodied energy environmental impacts in construction. However, when poorly designed, they may incur in high risk of mould growth, affecting both building performance and occupant's wellbeing. This research investigates the risk of mould growth associated with emerging timber envelopes in Australia, particularly looking at mass-timber and timber-framed wall typologies. The study compares the use of two mould growth assessment models: the VTT and the IBP biohygrothermal. Results provide relevant insights on both current design approaches and performance assessment methodologies. Whilst the study is based on Australian practice, conclusions have international relevance and applicability.
\end{abstract}

Keywords: hygrothermal performance; condensation risk; mould growth; WUFI; timber envelope design; mass-timber construction; Australian climate

\section{Introduction}

Humans spend almost $90 \%$ of their time indoors [1,2], which is reflected in increasingly higher requirements for the indoor air quality (IAQ) provision, meant as a combination of chemical, physical and biological factors. Chemical factors are all those parameters that express the concentration of substances or particles in the air, such as $\mathrm{PM}_{10}$ or $\mathrm{CO}_{2}$. The physical factors refer to the environmental parameters, such as temperature, humidity, airflow, lighting and noise. Biological factors relate to the presence of organic or biological substances, such as pollen, dust, bacteria and mould [3,4]. Biological factors have only recently gained the attention of the building regulation bodies in the Australian context. In 2015, the Australian Building Codes Board (ABCB) has conducted an investigation that shows how a third of the Australian building stock, both new and existing buildings, suffer from condensation and moisture-related problems [5].

The transition to the NCC (National Construction Code) 2019 [6] represents an important step towards more stringent energy-efficiency requirements, introducing thermal break, condensation and weatherproofing management sections. However, moisture management in building envelopes do not have clear and thorough deemed-to-satisfy provisions, and it is, therefore, unlikely to be addressed in practice.

Mould causes biodeterioration [7] and early degradation of building materials, resulting in a reduction of building components' service life [8] and high cost for repairs and maintenance $[9,10]$. Mould can also lead to poor indoor environmental quality conditions that may strongly impact human's health and well-being, with literature correlating the presence of mould to respiratory symptoms [11]. Mouldy environments are found in old buildings as well as newly built ones [12], identifying the issue as a broad problem across the sector that may manifest also only a few years after construction [13]. Among the factors that can be identified as primary causes of biological germination, there are architectural and design strategies that do not account for moisture-related issues, inappropriate 
maintenance and operational practices, such as underventilation of the indoor environments that lead to higher moisture loads [14-16]. The favourable conditions for mould to grow are determined by environmental parameters, such as temperature and humidity, as well as water and nutrient availability on the surface for the spores to germinate [17]. The latter are highly influenced by the construction materials in use, and specifically their vapour permeability, hygroscopic nature and presence of organic compounds within the matrix. Timber is one of the most suitable substrates for mould to proliferate [18]; thus, consequences deriving from poor design choices may be hindering its market acceptance along with the numerous benefits that the material would bring to the construction sector as per environmental impacts minimisation [19].

\section{The Australian Context}

Australia is today witnessing an increased interest in timber construction for the multi-storey residential and commercial markets. Recent Australian NCC amendments have allowed for the construction of mass-timber buildings of up to $25 \mathrm{~m}$ [20]. Large developers and builders are more often considering timber technologies as a feasible and preferable alternative to other structural solutions, due to the advantages they offer in terms of speed and ease of construction, higher site safety and marketing benefits [21,22]. However, building with timber requires extra care when it comes to moisture management, particularly for mid- to high-rise construction, as moisture-related problems may as well result in structural damages.

Australia presents a wide set of climatic conditions, some of them highly challenging in terms of temperature and humidity levels. The authors' previous studies in the field identified opportunities and limitations on the adoption of emerging timber-based envelopes in the Australian climatic context. It was pointed out the need for further investigation on the hygrothermal behaviour of such typologies to identify a solid performance framework and guide current construction practices to operate best practice in the field [23].

This research investigates the hygrothermal behaviour and assesses mould growth risk of multi-layered timber envelope systems across different major Australian cities. The analysis accounts for a wide range of wall assembly configurations, designed for compliance with the National Construction Code (NCC) [6].

\section{Research Methodology}

This study aims at better understanding and characterising the behaviour of emerging timber envelope solutions concerning mould growth risk across four different Australian climatic zones. The research scope mainly focuses on two distinct (but interdependent) domains:

- Design strategies optimisation, by critically addressing the complexity of building envelope integrated design. Therefore, the authors' objective is to identify efficient, reliable and durable envelope solutions that guarantee healthy environments for the occupants' wellbeing.

- Assessment strategies optimisation, by questioning current assessment practices and available regulatory frameworks. The authors investigate the impact that different assessment methodologies have on the results' reliability by comparing the two major methods for assessing mould growth risk in building materials and components.

The hygrothermal analysis is conducted on two main external wall typologies that are today being employed in the multi-story residential market in Australia: a masstimber wall that uses cross-laminated timber (CLT) as the structural support layer, and a lightweight timber-framed wall with in-cavity insulation. A standard wall configuration for each typology is used as a benchmark, and several variations of it are assessed against the same boundary conditions and assumptions. This methodology allows for a better understanding of the impact that design choices have on the hygrothermal performance of timber wall build-ups. The method of analysis consists of a step-by-step approach, with incremental simulations complexity. 


\subsection{Failure Criteria}

As mentioned, the analysis adopts a twofold assessment approach that comprises the use of both major mould growth models to investigates building components performance: the IBP biohygrothermal model, developed by Sedlbauer and based on isopleths [10,24], and the VTT model [25], which is the basis for the international building standard ASHRAE $160 \mathrm{P}$ [26].

The VTT model correlates temperature and relative humidity to the risk of mould growth, as a function of the sensitivity of the substrate and time of exposure. This model is empirical, based on visual inspection of mould coverage of material samples used in an experimental campaign. The favourable environmental conditions for growth are defined by the critical value of relative humidity (RHcrit), which refers to the lowest humidity that allows mould to grow on a substrate after a certain exposure time. RHcrit is a function of temperature. The growth risk is expressed by a mould index, which ranges between 0 and 6 . Germination is associated with an index equal to 1 , while the other values are associated with the percentage of mould coverage of the experimental samples, with 6 being $100 \%$. The final result of the growth assessment performed over a certain time is given by the incremental value of the mould index assessed at hourly time steps. For each time step, the conditions are assessed against RHcrit and, if the favourable conditions are not met, the model allows for either a delay or a decline in the mould index.

The IBP biohygrothermal model is based on the comparison between the transient temperature and relative humidity on the surface, with the conditions that sustain growth on typical building materials. This model correlates the growth phenomenon with the moisture balance at the spore level, considering the transient conditions of humidity and temperature at the boundary, and it accounts for substrate type, climatic conditions and the minimum requirements for spore germination. In this model, growth is allowed when the moisture content within a spore, which depends on the relative humidity of the air, reaches the critical value, which depends on temperature, relative humidity and substrate sensitivity. Unlike the VTT model, this allows us to determine the growth rate, expressed as the formation of mycelium in $\mathrm{mm} /$ day.

Interesting literature reviews focus on the core differences of these models and their implications on the results of the assessments $[16,27]$.

Both models are available to be used within the WUFI environment, and results are ranked in three classes, following the traffic light scheme: RED for an unacceptable level of risk, YELLOW when further investigations are needed and GREEN when the risk is acceptable. Table 1 indicates the ranking criteria used to define the level of risk.

Table 1. Indication of the values of the traffic light scheme for the two different assessment models.

\begin{tabular}{cccc}
\hline Traffic Light & Level of Risk & $\begin{array}{c}\text { VTT Model } \\
\text { Mould Index MI (-) } \\
\text { ASHRAE 160 Limit }\end{array}$ & $\begin{array}{c}\text { IBP Model } \\
\text { Mould Growth (mm/year) and } \\
\text { Corresponding MI Value }\end{array}$ \\
\hline Green & Usually acceptable & MI $<1$ & $\begin{array}{c}\text { growth }<50 \\
(\text { MI }<0.5)\end{array}$ \\
Yellow & Additional investigations are needed & $1<\mathrm{MI}<3$ & $\begin{array}{c}50<\text { growth }<200 \\
(\text { MI: } 0.5<\text { MI }<2) \\
\text { growth }>200 \quad \\
(\text { MI }>2)\end{array}$ \\
\hline
\end{tabular}

\subsection{Simulation Set-Up}

The hygrothermal performance assessment was run via the software WUFI Pro [28], which is one of the most reliable commercial software developed by the Fraunhofer Institute of Building Physics in Munich (Germany). The envelope assessment is based on a validated model that allows for a realistic calculation of the hygrothermal performance in multilayered building components. The heat transfer accounts for conduction, enthalpy flows, short-wave and long-wave radiative components, while the moisture transfer occurs by 
vapour diffusion, capillary liquid transfer and liquid surface diffusion. The whole building tool couples the benefit of the envelope analysis with the features that characterise thermal transient assessments. The software accounts for eventual moisture sources and sinks within the room, the moisture exchange with the envelope through capillarity, diffusion and sorption-desorption phenomena as well as standard indoor and outdoor thermal exchanges [29].

\subsection{Boundary Conditions and Assumptions}

\subsubsection{Wall Typologies and Assemblies}

The analysis aims to understand potential criticalities arising with moisture transfer through timber-based envelope systems that are currently being used in the multi-story residential building market in Australia. These typologies are generally employed in industrialised construction, thus being manufactured off-site and transported to the construction site ready to be installed in their final position. This is an important advantage when it comes to the moisture safety of timber structures. Prefabrication contributes to consistently reducing construction time and, therefore, building elements' exposure to unfavourable weather. It also allows to protect sensitive materials, as it is timber, while still in factories, and ship it to the site already equipped with weatherproofing.

As mentioned above, two wall typologies are being assessed against mould growth risk: a CLT-based wall and a timber-framed one. Functional layers' selection and arrangement for the two envelope typologies are representative of market solutions from the construction practice. Both envelope typologies are designed to meet the minimum thermal and structural regulatory requirements prescribed by the Australian Building Code [6]. The selected zones account for the main Australian cities where most of the population lives and multi-residential buildings are more commonly found. In particular, the analysis includes climate zones 2 (Brisbane), 5 (Adelaide, Perth and Sydney), 6 (Melbourne) and 7 (Canberra). Figure 1 shows the two standard configurations used as a benchmark to design configuration variations and to analyse hygrothermal performance sensitivity for those variations. Table 2 reports the wall build-up's description, indicating material and thickness for each layer. Table 3 reports materials/products properties of the selected wall assembly that were retrieved from the WUFI built-in extensive database. Different brands of the same material product may be characterised by slightly different hygrothermal behaviour, especially if the product is timber-based, where the species also play an important role in determining the response to moisture input [30,31]. However, a standard methodology in simulation studies to overcome this issue is to use the in-built WUFI database [23,32-35], which specifies the CLT species (spruce) and provides validated performance data for the others. Indeed, this database includes the specification of the major building products, tested and validated experimentally at the Fraunhofer Institute of Building Physics Laboratories in Munich, according to the relevant building codes and regulations.

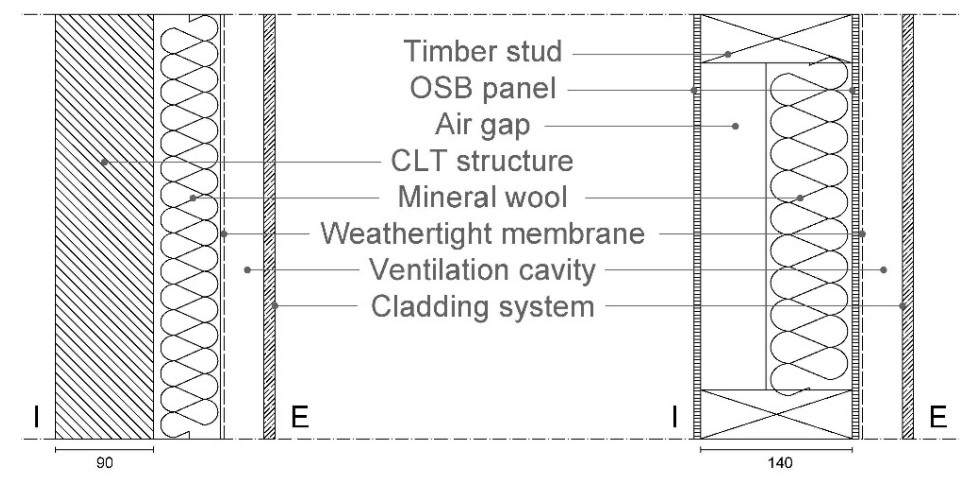

Figure 1. Schematic representation of the wall assemblies used as two reference scenarios: Masstimber (CLT) wall on the left, and Timber-framed (TF) wall on the right. I: internal surface, E: external surface [23]. 
Table 2. Wall assemblies' description. Layers are listed from indoor to outdoor, minimum R-value requirements for each climate zone [6] is noted.

\begin{tabular}{|c|c|c|c|c|c|}
\hline \multirow[t]{2}{*}{ Wall Typologies } & \multirow{2}{*}{$\begin{array}{c}\text { Functional Layer } \\
\text { CLT structure (spruce) }\end{array}$} & \multicolumn{4}{|c|}{ Layer Thickness (mm) } \\
\hline & & 90 & 90 & 90 & 90 \\
\hline \multirow{4}{*}{ Mass-timber wall } & Mineral wool & 80 & 60 & 60 & 60 \\
\hline & Weathertight membrane & $<1$ & $<1$ & $<1$ & $<1$ \\
\hline & Ventilated cavity & 50 & 50 & 50 & 50 \\
\hline & Cladding system & 10 & 10 & 10 & 10 \\
\hline \multirow{7}{*}{ Timber-framed wall } & OSB panel & 12.5 & 12.5 & 12.5 & 12.5 \\
\hline & Air gap & 40 & 60 & 60 & 60 \\
\hline & Mineral wool & 100 & 80 & 80 & 80 \\
\hline & OSB panel & 12.5 & 12.5 & 12.5 & 12.5 \\
\hline & Weathertight membrane & $<1$ & $<1$ & $<1$ & $<1$ \\
\hline & Ventilated cavity & 50 & 50 & 50 & 50 \\
\hline & Cladding system & 10 & 10 & 10 & 10 \\
\hline \multirow{6}{*}{ Variants } & 1-Vapor barrier & $<1$ & $<1$ & $<1$ & $<1$ \\
\hline & 2-Fire barrier & 13 & 13 & 13 & 13 \\
\hline & 3-Plywood & 12.5 & 12.5 & 12.5 & 12.5 \\
\hline & 4-Mineral wool (high density) & 40 & 40 & 40 & 40 \\
\hline & Climate zone & 2 & 5 & 6 & 7 \\
\hline & R-value limit $\left[\mathrm{K} \cdot \mathrm{m}^{2} / \mathrm{W}\right]$ & 3.3 & 2.8 & 2.8 & 2.8 \\
\hline
\end{tabular}

Table 3. Material properties of the wall layers for each typology.

\begin{tabular}{|c|c|c|c|c|c|c|}
\hline Wall Typologies & Functional Layer & $\begin{array}{l}\text { Bulk Density } \\
\left(\mathrm{kg} / \mathrm{m}^{3}\right)\end{array}$ & $\begin{array}{l}\text { Porosity } \\
\left(\mathrm{m}^{3} / \mathrm{m}^{3}\right)\end{array}$ & $\begin{array}{c}\text { Heat } \\
\text { Capacity } \\
(\mathrm{J} / \mathrm{kg} \mathrm{K})\end{array}$ & $\begin{array}{c}\text { Thermal } \\
\text { Conductivity } \\
\text { Dry } \\
(\mathrm{W} / \mathrm{mK})\end{array}$ & $\begin{array}{c}\text { Water } \\
\text { Vapour } \\
\text { Diffusion } \\
\text { Resistance Dry } \\
(-)\end{array}$ \\
\hline \multirow{8}{*}{ Mass-timber wall } & CLT structure & 410 & 0.74 & 1300 & 0.098 & 500 \\
\hline & Mineral wool & 135 & 0.953 & 1030 & 0.038 & 1.1 \\
\hline & Weathertight membrane & 130 & 0.001 & 2300 & 2.3 & 200 \\
\hline & Ventilated cavity & \multicolumn{5}{|c|}{ Air layer without additional moisture capacity } \\
\hline & Cladding system & 675 & 0.71 & 850 & 0.2 & 8.33 \\
\hline & OSB panel & 615 & 0.9 & 1500 & 0.13 & 175 \\
\hline & Air gap & \multicolumn{5}{|c|}{ Air layer without additional moisture capacity } \\
\hline & Mineral wool & 73 & 0.95 & 850 & 0.032 & 1.1 \\
\hline \multirow{4}{*}{ Timber-framed wall } & OSB panel & 615 & 0.9 & 1500 & 0.13 & 175 \\
\hline & Weathertight membrane & 130 & 0.001 & 2300 & 2.3 & 200 \\
\hline & Ventilated cavity & \multicolumn{5}{|c|}{ Air layer without additional moisture capacity } \\
\hline & Cladding system & 675 & 0.71 & 850 & 0.2 & 8.33 \\
\hline \multirow[t]{4}{*}{ Variants } & 1-Vapour barrier & 130 & 0.001 & 2300 & 2.3 & $1,500,000$ \\
\hline & 2-Fire barrier & 850 & 0.65 & 850 & 0.2 & 8.3 \\
\hline & 3-Plywood & 500 & 0.5 & 1400 & 0.1 & 700 \\
\hline & $\begin{array}{l}\text { 4-Mineral wool } \\
\text { (high density) }\end{array}$ & 178 & 0.934 & 850 & 0.0336 & 1.76 \\
\hline
\end{tabular}

Considering the standard configurations as reference scenarios, a series of incremental steps were used to assess the hygrothermal behaviour of a series of configuration variations and more complex wall build-ups. Each step on analysis focuses on the variation of one specific layers' position or material at a time.

The CLT-based wall solution counted three incremental steps of analysis (refer to Figure S1), specifically varying:

1. Variant 1-Moisture control layers (weathering membrane and vapour barrier). This set of simulations aims to assess the influence of the location of the weather and vapour barriers within the wall build-ups. Different configurations are tested, including a variant where the moisture control layers are placed at the interface between the CLT and the insulation. This strategy is sometimes used in CLT construction 
to quickly protect timber structures from the weather and to minimise the risk of moisture damage during construction works.

2. Variant 2-Fire barrier (gypsum board). This set of simulations investigates the impact that the fire protection layer has on the hygrothermal performance of the wall assembly. Indeed, NCC compliance for timber-based envelopes requires the encapsulation of the timber structure within incombustible fire-resistant boards. Depending on the fire resistance level (FRL) rating required, a wall can be encapsulated in one or more fire rated boards.

3. Variant 3-Sheeting (OSB or plywood). This set of simulations explores the use of a bracing board on the outside of the insulation and its influence on the wall buildup's moisture safety. This solution may be employed in prefabricated large-size wall elements to both increase the rigidity and robustness of the component during on-site operations, as well as for factory logistics reasons (to ease the installation of the insulation layer and speed up off-site assembly operation). The analysis includes two different products that are highly diffused on the Australian market, namely the oriented strand board (OSB) and plywood.

The timber-framed wall solution counted four incremental steps of analysis (refer to Figure S2), specifically varying:

1. Variant 1-Moisture control layers (weathertight membrane and vapour barrier). As per the CLT wall solution, this simulation set aims to assess the impact on the moisture control layers' placement within the wall assembly. This time, the membrane permeability is also varied to try and improve the overall hygrothermal behaviour.

2. Variant 2-Fire barrier (gypsum board). As per the CLT wall solution, the presence of fire protective bards is assessed.

3. Variant 3-Sheeting (OSB or plywood or rigid insulation). As per the CLT wall solution, this set of simulations investigates the use of OSB or plywood within the wall cross-section according to different configurations. One option also considers the use of a rigid high-density mineral wool insulation panel to be installed on the outside of the wall frame, in place of the external OSB or plywood bracing board.

4. Variant 4-Insulation. This set of simulations explores the effects that the insulation position within the wall build-up has on the hygrothermal behaviour of the timber-framed solution. The impact of the change of the wall R-value (improved thermal performance) is also assessed. In timber-framed walls, the insulation layer is usually within the frame. NCC deemed-to-satisfy provisions for the envelope thermal performance across the various Australian climatic contexts are generally met with a reduced insulation thickness. This results in the wall cavity only partially filled. This solution is cost-effective, but it might as well cause moisture-related issues and condensation accumulation hidden within the cavity and, therefore, is hard to detect at early stages.

Figures S1 and S2 show the different simulated scenarios, respectively, for the masstimber and the timber-framed walls.

\subsubsection{Outdoor Climate}

Four different climate zones of Australia are included in this study, which account for the most populated cities of the nation. In particular, zone 2 (Brisbane), zone 5 (Adelaide, Perth, Sydney), zone 6 (Melbourne) and zone 7 (Canberra). Table 4 summarises the type of climate for the 4 zones.

Transient hygrothermal simulations compute the heat and moisture hourly profiles within the building components starting from hourly climatic inputs to characterise the hygrothermal performance with a reliable time-step. The climatic file used is the typical meteorological year file (TMY), generated by METENORM [36]. TMY contain standard climatic conditions of a location based on the statistical average of the previous years. When monitored data for the specific location is not available, the file is generated through interpolation of the available records. 
Table 4. Description of the climatic zone according to [6].

\begin{tabular}{ccc}
\hline Climate Zone & Description & Reference City \\
\hline 2 & Warm humid summer, mild winter & Brisbane \\
5 & Warm temperate & Adelaide, Perth, Sydney \\
6 & Mild temperate & Melbourne \\
7 & Cool temperate & Canberra \\
\hline
\end{tabular}

\subsubsection{Indoor Climate}

The authors' previous studies demonstrated that hygrothermal simulations are highly influenced by indoor climate selection and modelling [23]. The indoor climate for hygrothermal simulations comprises temperature and humidity hourly profiles, which depend on a broad number of factors, such as occupancy, activities performed indoors and HVAC profile. These parameters are rarely known upfront during the design stage; hence, they are defined based on standard and simplified assumptions, often indicated by the regulatory framework.

This study follows the approach included in the ASHRAE 160 P [26] where the temperature and humidity depend on the hourly outdoor profile, as described in Table 5 (temperature) and Table 6 (humidity).

Table 5. Hourly indoor design temperature (T).

\begin{tabular}{|c|c|c|}
\hline \multirow{2}{*}{$\begin{array}{c}24 \text { h Outdoor } \\
\text { Running Mean }\end{array}$} & \multicolumn{2}{|c|}{ Indoor Temperature Design } \\
\hline & Heating Only & Heating + AC \\
\hline $\mathrm{T}_{\mathrm{o}, 24}<18.3^{\circ} \mathrm{C}$ & $21.1{ }^{\circ} \mathrm{C}$ & $21.1^{\circ} \mathrm{C}$ \\
\hline $18.3^{\circ} \mathrm{C}<\mathrm{T}_{\mathrm{o}, 24}<21.1^{\circ} \mathrm{C}$ & $\mathrm{T}_{\mathrm{O}, 24}+2.8^{\circ} \mathrm{C}$ & $\mathrm{T}_{\mathrm{O}, 24}+2.8^{\circ} \mathrm{C}$ \\
\hline $\mathrm{T}_{\mathrm{o}, 24}>21.1^{\circ} \mathrm{C}$ & $\mathrm{T}_{\mathrm{O}, 24}+2.8^{\circ} \mathrm{C}$ & $23.9^{\circ} \mathrm{C}$ \\
\hline
\end{tabular}

Table 6. Hourly indoor design relative humidity $(\mathrm{RH})$.

\begin{tabular}{cc}
\hline Daily Average Outdoor Temperature & Design Indoor Relative Humidity \\
\hline $\mathrm{T}_{\mathrm{o} \text {,day }}<10{ }^{\circ} \mathrm{C}$ & $40 \%$ \\
$10{ }^{\circ} \mathrm{C}<\mathrm{T}_{\mathrm{o}, \text { day }}<2{ }^{\circ} \mathrm{C}$ & $40 \%+\left(\mathrm{T}_{\mathrm{o}, \text { day }}+10\right) \%$ \\
$\mathrm{~T}_{\mathrm{o} \text {,day }}>20{ }^{\circ} \mathrm{C}$ & $70 \%$ \\
\hline
\end{tabular}

\subsubsection{Simulation Matrix}

The various parameters are used to create a simulation matrix that encompasses 312 simulations, generated by linear combination. Figure 2 shows the combination process, whereas the red lines indicate all the possible combinations between wall technology, technological variant, indoor climate, outdoor climate and post-processor used. 


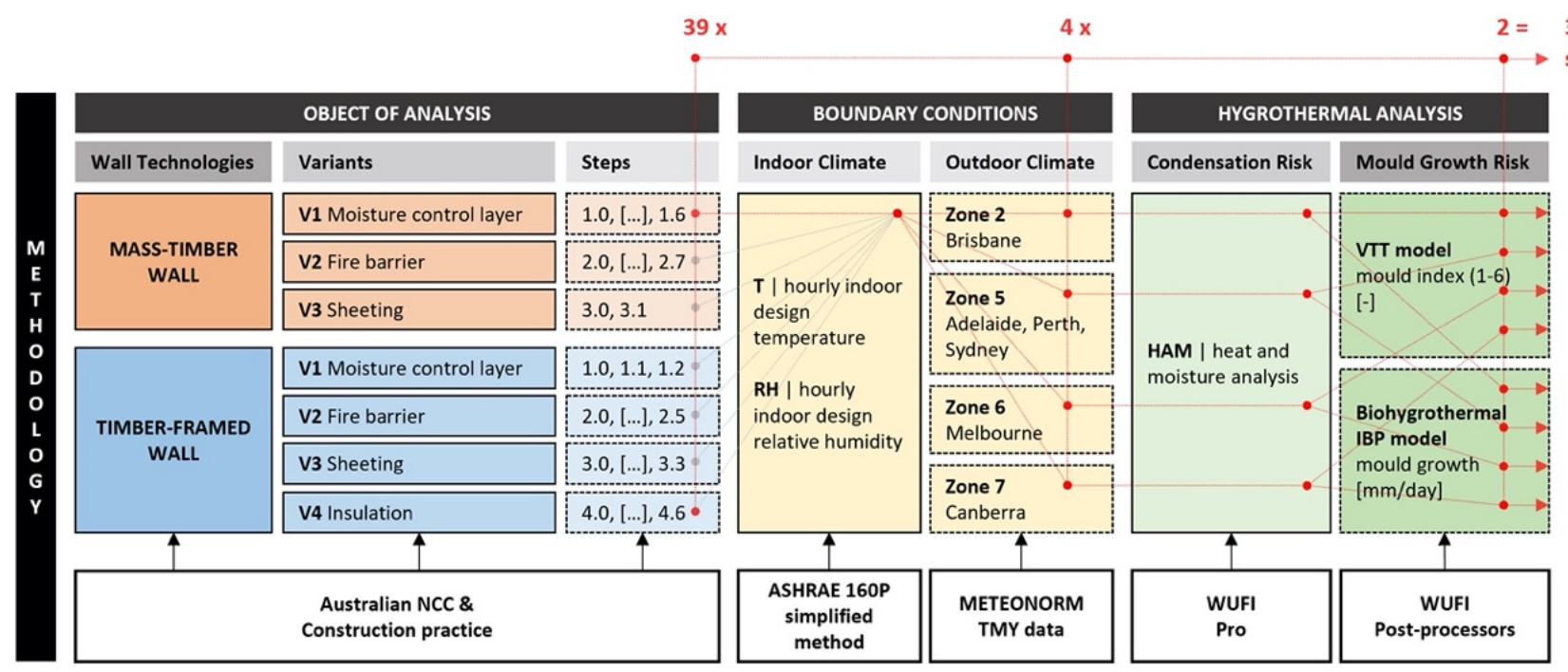

Figure 2. Visual representation of the combinations of the various parameters used in the analysis to generate the scenarios. The red lines indicate how these parameters (wall technology, variants, indoor and outdoor climates, post-processing) are combined to reach the final simulation matrix.

\section{Results and Discussion}

The number of convergence failures is usually considered as a good proxy for the calculation process quality. However, this number must be read in conjunction with the moisture balances. If the total water content balance results equal, or are close to, the sum of the moisture fluxes across the surfaces, it means that the results are acceptable, despite possible convergence failure. The simulations performed for this analysis did not show any major issues. Some scenarios presented a few convergence errors (usually below 5), which are not reasons for concern as the moisture balances difference acceptable results.

The total water content trend for the high majority of the simulated scenarios followed seasonal variations, without any critical accumulation in time. The only exception is represented by the timber-framed wall solution in climate 6 (both for the VTT and IBP assessment models), where water is accumulated in the proximity of the OSB external surface right behind the weathering membrane, indicating a potential durability issue.

The analysis unveils a small yet significant difference between the two methods of assessment of mould growth risk for building materials and components, namely the IBP biohygrothermal model and the VTT one. Results for both the wall typologies show how the IBP assessment model is more conservative than the VTT one, which means that choosing one over the other might increase the chances for a proposed technical solution to comply with the code and be considered reliable. This discrepancy of results between the two assessment methods calls for an urgent update of the national regulatory body, which currently does not prescribe a numerical approach to mould growth. It also highlights the importance of rationalising international building standards, which lack consistency and an agreed framework [17].

\subsection{Mass-Timber Wall}

Figure 3 shows the mould risk value of the reference scenario assessed according to VTT and IBP models. The background colour of the graph identifies the traffic light scheme thresholds, as indicates by Table 1 . The graph shows the results obtained for the 10th year of the assessment. In the IBP model, the yearly growth rate is constant over time, due to the use of TMYs; hence, the 10th year is representative of any year of the assessment time window. In the VTT model, instead, the last year represents the stabilised situation, where the initial conditions do not have influence. 

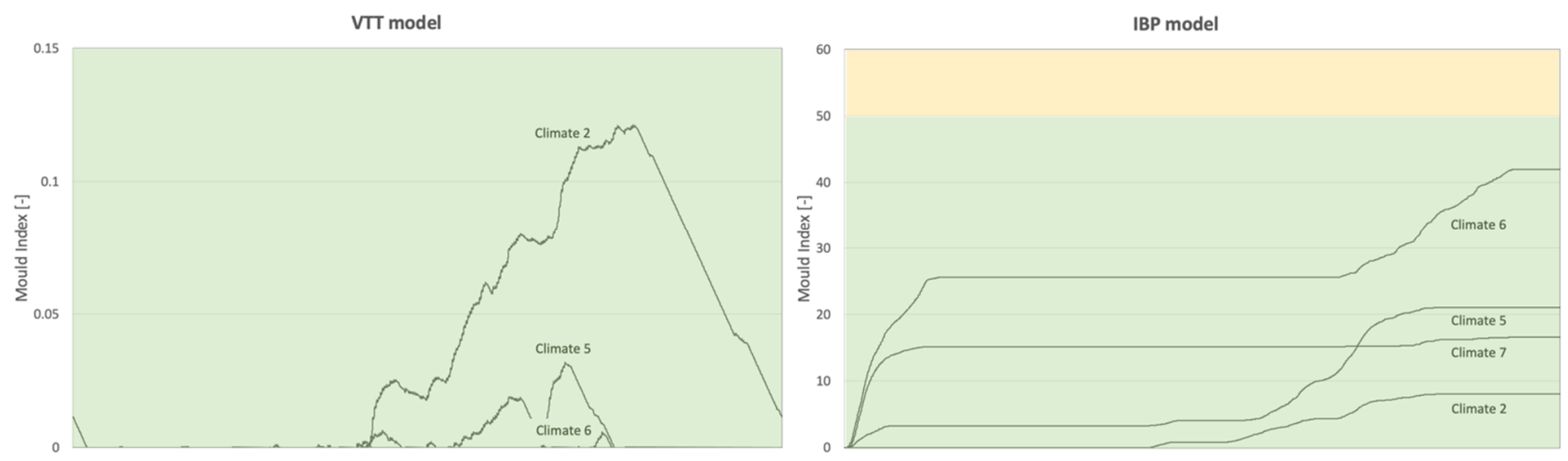

Figure 3. Mould Index value of the reference scenario in the different climates assessed with VTT and IPB model; only the values for the most critical interface are reported (most critical interface: external surface of the insulation layer).

Although the reference scenario results below the critical thresholds in both models for all climates, the trends are significantly different. According to the VTT assessment, the climates that present the most critical trends are climate 2 and 5, while climate 6 and 7 have an MI close to 0 . This seems to suggest that this model is particularly sensitive in warmer climates. On the opposite, when the analysis accounts for the mould growth rate according to the IBP model, the ranking results in Climate 6, 5, 7 and lastly climate 2 . In this second case, it is worth noticing the peculiarity of Climate 5 , which shows a significant ramp in the growth rate toward the end of the graph. This is mainly due to the climatic condition of Sydney, characterised by both hot summers with high solar radiation and cool winters with few rigid days. The high variability of the external climates makes this scenario a mix of the worst conditions found in climate 2 and climate 6.

Table 7 reports the results obtained for the mass-timber (CLT) wall. This construction solution is highly resilient to hygrothermal stresses; indeed, the risk of mould growth is particularly low in all climates.

Table 7. Results of the mould growth risk assessment for various mass-timber wall configurations.

\begin{tabular}{cccccccccc}
\hline \multirow{2}{*}{ Variant } & \multirow{2}{*}{ Scenarios } & \multicolumn{2}{c}{ Climate Zone 2 } & \multicolumn{2}{c}{ Climate Zone 5 } & \multicolumn{2}{c}{ Climate Zone 6 } & \multicolumn{2}{c}{ Climate Zone 7 } \\
\cline { 2 - 8 } & & VTT & IBP & VTT & IBP & VTT & IBP & VTT & IBP \\
\hline Ref. Scenario & 0 & Green & Green & Green & Green & Green & Green & Green & Green \\
\hline & 1.0 & Green & Green & Green & Green & Green & Green & Green & Green \\
& 1.1 & Yellow & Red & Red & Red & Red & Red & Red & Red \\
Variant 1 & 1.2 & Green & Yellow & Green & Green & Green & Yellow & Green & Yellow \\
& 1.3 & Green & Green & Green & Green & Green & Green & Green & Green \\
Moisture control layers & 1.4 & Green & Green & Green & Green & Green & Green & Green & Green \\
& 1.5 & Green & Yellow & Green & Yellow & Green & Yellow & Green & Yellow \\
& 1.6 & Green & Green & Green & Green & Green & Green & Green & Green \\
\hline & 2.0 & Green & Green & Green & Green & Green & Green & Green & Green \\
& 2.1 & Green & Green & Green & Green & Green & Green & Green & Green \\
& 2.2 & Green & Green & Green & Green & Green & Green & Green & Green \\
Variant 2 & 2.3 & Green & Green & Green & Green & Green & Green & Green & Green \\
Fire barriers & 2.4 & Green & Green & Green & Green & Green & Green & Green & Green \\
& 2.5 & Green & Green & Green & Green & Green & Green & Green & Green \\
& 2.6 & Green & Green & Green & Green & Green & Green & Green & Green \\
& 2.7 & Green & Green & Green & Green & Green & Green & Green & Green \\
\hline Varian 3 & 3.0 & Yellow & Red & Yellow & Red & Yellow & Red & Yellow & Red \\
Sheeting & 3.1 & Green & Yellow & Green & Yellow & Green & Yellow & Green & Yellow \\
\hline
\end{tabular}

Variant 1 investigates the use of moisture control layers and their position within the wall build-up. The most critical scenario is 1.1 which corresponds to the design solution that uses a non-breathable weathering membrane (therefore acting as a vapour barrier) 
on the external side of the insulation layer. This solution is highly vulnerable in cool and cold climates, such as 5, 6 and 7, where the hygrothermal transfer mainly happen toward the outside. In this case, the failure occurs at the surface between the insulation and the vapour barrier, consistently across all climates. Moreover, in climate zones 6 and 7, there is an additional risk of mould germination at the interface between the insulation and the CLT structure (yellow risk-IBP model only). The same risk for mould growth, yet reduced in magnitude, can be observed for scenarios 1.2 and 1.5, where the vapour barrier is placed at the interface between the CLT structural element and the insulation layer. In these two cases, the risk of failure is located at the interface between the CLT and the vapour barrier across all climates, suggesting that the moisture may very likely be trapped from the vapour barrier in the proximity of the mass-timber element. Early biodegradation of the structural material may lead to severe consequences for the building structural integrity and safety, as well as resulting in onerous remediation expenses.

The investigation conducted on moisture control layers (both weathertight membrane and vapour barrier) confirms that, as a general rule, moisture-open design strategies are recommended in timber envelope design because higher water vapour permeability of wall components allows for the moisture to be dried out more efficiently. The use of a vapour barrier on the internal side of a mass-timber wall should be carefully considered and only used when necessary. This might be the case for highly humid indoor environments such as bathrooms or confined kitchens. The configurations showcasing the vapour barrier in the outside of the wall structural layer (scenarios 1.1, 1.2 and 1.5), were all tested on purpose, despite being obviously inaccurate. Indeed, the authors wanted to stress the fact that a wrong moisture-control design strategy (as in the case of the vapour barrier misplacement) may cause severe consequences. This is particularly relevant for designers when selecting the weathering membrane for their wall build-ups. Choosing a product with a low permeability rate may consistently increase the risk of biological germination.

Variant 2 simulation steps explore the effect that fire protective boards can have on the timber envelope hygrothermal performance. Results show how the presence of fire barriers do not influence much the performance of the mass-timber envelope solution concerning the risk of mould growth. Conversely, when using a sheeting board (OSB or plywood) on the outside of the insulation, such as the one used for variant 3 , the hygrothermal behaviour of the wall build-up may considerably change. Should a similar technical solution be required, the use of plywood boards, rather than the OSB ones, is recommended. Although plywood's vapour dry permeability (measured when the material is completely dry) is higher than the permeability of OSB, as indicated in Table 3, this value drastically changes at higher relative humidity. Indeed, plywood vapour permeability at $\mathrm{RH} 50 \%$ is approximately 200, and it further drops at 20 at $\mathrm{RH} 100 \%$, resulting in a more appropriate solution for timber-based envelopes under ambient relative humidity and guaranteeing good wall breathability. This confirms again how moisture-open design approaches are always preferable when dealing with timber buildings.

\subsection{Timber-Framed Wall}

Figure 4 shows the mould risk value of the reference scenario assessed according to VTT and IBP models. The background colour of the graph identifies the traffic light scheme thresholds, as indicates by Table 1 . 
VTT model

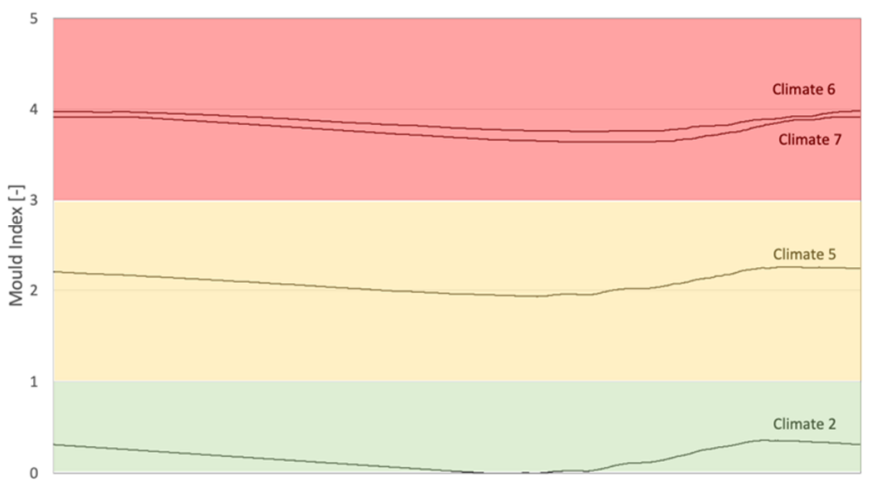

IBP model

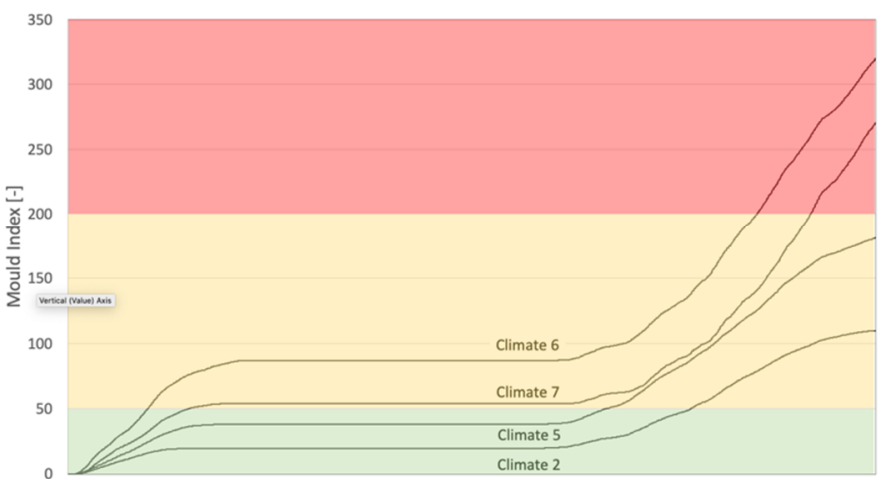

Figure 4. Mould Index value of the reference scenario in different climates assessed with VTT and IPB model. The yellow and red lines indicate the index. Only the results for the most critical interface are shown (most critical interface: external surface of the insulation in contact with the OSB).

These trends completely differ from the ones observed for the massive timber solution, with greater consistency in the climate ranking of the severity of the growth issue across the two models. It is worth noticing that Climate 7 in the IBP model follows a steeper curve, indicating that the timber frame solution is particularly sensitive to cold climates. Considering that the reference scenario represents the current practice in Australia, designed according to the Building Code, this result suggests that the thermal requirements are not sufficient to guarantee an optimal hygrothermal behaviour for this type of build-up.

Table 8 shows the results obtained for the timber-framed wall hygrothermal assessment. Unlike the previous wall typology, timber framing presents a high risk of mould growth for most of the selected wall configurations and consistently across the different climates. As a general observation, it can be noted how the IBP model is more conservative than the VTT one, which confirms observations made for the assessment of mass-timber walls.

Table 8. Results of the mould growth risk assessment for various timber-framed wall configurations.

\begin{tabular}{|c|c|c|c|c|c|c|c|c|c|}
\hline \multirow{2}{*}{ Variant } & \multirow{2}{*}{ Scenarios } & \multicolumn{2}{|c|}{ Climate Zone 2} & \multicolumn{2}{|c|}{ Climate Zone 5} & \multicolumn{2}{|c|}{ Climate Zone 6} & \multicolumn{2}{|c|}{ Climate Zone 7} \\
\hline & & VTT & IBP & VTT & IBP & VTT & IBP & VTT & IBP \\
\hline Ref. Scenario & 0 & Green & Yellow & Yellow & Yellow & Red & Red & Red & Red \\
\hline \multirow{3}{*}{$\begin{array}{c}\text { Variant } 1 \\
\text { Moisture control layers }\end{array}$} & 1.0 & Green & Yellow & Green & Yellow & Green & Yellow & Green & Yellow \\
\hline & 1.1 & Yellow & Yellow & Red & Red & Red & Red & Red & Red \\
\hline & 1.2 & Green & Yellow & Green & Yellow & Red & Red & Red & Red \\
\hline \multirow{6}{*}{$\begin{array}{c}\text { Variant } 2 \\
\text { Fire barriers }\end{array}$} & 2.0 & Green & Yellow & Yellow & Yellow & Red & Red & Red & Red \\
\hline & 2.1 & Green & Yellow & Yellow & Yellow & Red & Red & Red & Red \\
\hline & 2.2 & Green & Yellow & Yellow & Yellow & Red & Red & Red & Red \\
\hline & 2.3 & Green & Yellow & Yellow & Yellow & Yellow & Red & Red & Red \\
\hline & 2.4 & Green & Yellow & Yellow & Yellow & Yellow & Red & Red & Red \\
\hline & 2.5 & Green & Yellow & Yellow & Yellow & Yellow & Red & Red & Red \\
\hline \multirow{4}{*}{$\begin{array}{l}\text { Variant } 3 \\
\text { Sheeting }\end{array}$} & 3.0 & Green & Green & Green & Yellow & Green & Yellow & Green & Yellow \\
\hline & 3.1 & Green & Yellow & Yellow & Yellow & Red & Red & Red & Red \\
\hline & 3.2 & Green & Green & Green & Green & Green & Yellow & Green & Yellow \\
\hline & 3.3 & Green & Yellow & Green & Green & Green & Green & Green & Green \\
\hline \multirow{7}{*}{$\begin{array}{l}\text { Variant } 4 \\
\text { Insulation }\end{array}$} & 4.0 & Green & Yellow & Yellow & Red & Red & Red & Red & Red \\
\hline & 4.1 & Green & Green & Green & Green & Green & Yellow & Green & Yellow \\
\hline & 4.2 & Green & Green & Green & Green & Green & Green & Green & Green \\
\hline & 4.3 & Green & Green & Green & Yellow & Yellow & Yellow & Yellow & Yellow \\
\hline & 4.4 & Green & Yellow & Yellow & Yellow & Red & Red & Red & Red \\
\hline & 4.5 & Green & Green & Green & Green & Green & Yellow & Green & Yellow \\
\hline & 4.6 & Green & Green & Green & Green & Green & Green & Green & Green \\
\hline
\end{tabular}

Variant 1 simulation steps, which investigate the use of moisture controls' layers within the wall, show how placing a vapour barrier on the inner side of the wall build-up 
(as per scenario 1.0) can be beneficial for timber-framed envelopes in colder climates. Conversely, the placement of a vapour barrier on the outside of the wall (as per scenario 1.1) proves highly inappropriate, as expected, across all the climates analysed. This confirms the authors' previous studies about vapour barrier mispositioning in timber-based envelopes [37]. Scenario 1.2 presents the same wall set-up as per the reference scenario (step 0); however, this time, it uses a weathering membrane with improved permeability. This configuration shows a slightly better wall behaviour in climate 5 against the VTT assessment method.

Variant 2 concerns the use of fire-resistant boards as a strategy for protecting timberbased envelopes through encapsulation. Results are in line with findings from the masstimber wall simulations, which show how the use of fire barriers do not relevantly affect the envelope performance with respect to moisture safety. Conversely, the use of different types of sheeting boards can strongly influence envelope hygrothermal performance. Indeed, substituting OSB bracing board with a more permeable material such as plywood (as per scenario 3.0) showed a significant reduction of the risk of mould growth across all climates. Scenarios 3.2 and 3.3 both use a $40 \mathrm{~mm}$ rigid insulation panel in place of the OSB bracing board on the outside of the wall build-up. These configurations present an improved permeability compared with the reference scenario (Step 0), demonstrating again how the use of vapour permeable materials in timber construction is highly recommended in order to prevent interstitial condensation and moisture-related damages in building components.

Variant 4 simulation steps investigate the impact of the insulation position within the wall build-up and observe as well how improving the wall thermal performance may affect the hygrothermal behaviour of the various configurations. In general, it can be noted how changing the position of the insulation inside the cavity (towards the inside or outside of the wall build-up) does not give back any substantial difference in the wall hygrothermal behaviour. However, those scenarios that include a layer of insulation on the outside of the wall build-up perform considerably better across all climates. In particular, simulation steps 4.2 and 4.6 , which present the same R-value as the reference scenario, present no verified failure across all the different climate zones, independently from the insulation position within the cavity. This indicates that high vapour-resistant layers, such as OSB, should be thermally protected to decrease the risk of mould growth. This strategy would increase the temperature at the vapour-resistant layer interface preventing possible condensation phenomena.

The wall configuration in scenario 4.0 presents an improved R-value. Moreover, the wall cavity is filled with insulation. In this case, the hygrothermal behaviour is very similar to the reference scenario (step 0) with a slightly worse outcome for climate 5 (biohygrothermal assessment model). Scenarios 4.1 and 4.5 present the same thermal performance of scenario 4.0; however, the use of an insulation layer on the outside of the OSB board gives back, again, significantly better results with respect to mould growth risk, consistently across the various climates. By merely looking at the incremental improvement of the wall thermal performance (e.g., step 4.2, 4.1 and 4.3, in this order), it is interesting to notice how the higher the thermal resistance in climate zones 5,6 and 7 (colder climates), the lower the wall hygrothermal behaviour. This is in line with previous research on the topic that highlighted how the higher the thermal resistance of a timber-framed exterior wall, the longer the drying out period and therefore the risk of mould growth [38].

Results also show that colder climates, such as 6 and 7, are more likely to present an unacceptable risk of mould growth over time, while its occurrence is detected also for climates 5 and 2 but with lower associated risks (yellow colour). This may indicate that the Australian design and construction practice are currently more focused and attentive to warm and hot climates, often overlooking climate regions characterised by a continental climate.

\section{Conclusions}

This paper presents a thorough study of the hygrothermal behaviour of emerging timber-based envelopes in Australia. The research objective is twofold. It aims at providing 
guidelines for the best practice design of timber envelopes in Australia by analysing the impact of functional layers and wall design decisions on the overall wall build-up performance. It also investigates the reliability of current methodologies to assess mould growth risk in construction. The transient hygrothermal assessments are performed over 10 years with the commercial hygrothermal software WUFI.

The study is particularly interesting as it analyses a relevant number of different technical design solutions for both mass timber and timber-framed typical wall technologies across four different climatic contexts. In particular, the incremental simulation steps explore the hygrothermal behaviour of different wall configurations by varying their moisture control strategies, fire performance, use of different sheeting materials and insulation layer integration within the wall build-up. The results show that the timber-framed envelope solution is more likely to fail and present mould growth issues over the years compared with mass-timber envelopes, which instead perform consistently better across all the different climates. However, the use of an additional insulation layer placed on the outside of the timber-framed wall helps to significantly reduce the risk of mould growth by preventing possible condensation phenomena at the interface with the OSB sheeting. This result indicates that the current thermal requirements of the Australian Building Code are not sufficient to provide a hygrothermal-resilient technical solution. Furthermore, the findings demonstrated how the adoption of moisture-open strategies is always recommended in timber-based envelopes. This implies the use of vapour permeable membranes and material which favour the efficient drying out of the envelope components, thus preventing interstitial condensation phenomena and moisture accumulation. Currently, the Australian Building Code does not capture this peculiarity, and it provides standard guidelines for the use of membranes based on the thermal climate zone, rather than accounting for the construction solution adopted.

In general, this study emphasises how the hygrothermal performance of multi-layered envelopes depends on several interdependent factors that have to be addressed simultaneously (such as functional layer positioning, material properties, wall specific performance concerning the various requirements and so on.). Thus, it is of paramount importance to systematically integrate moisture safety verifications within the design process and assess the hygrothermal performance of envelope components since the early stages of a project.

Another important observation regards the comparison of two different mould growth assessment models is: The biohygrothermal model appears to be more conservative than the VTT one, often resulting in a higher risk of mould growth. This discrepancy is explained by the different mathematical model used in the two assessments, and it reflects the peculiarity of this biological phenomenon which is difficult to characterise due to its biological unpredictable nature. For this reason, newly developed models adopt probabilistic approaches to performance assessment $[18,39,40]$. However, these methods require specialistic expertise that can hardly be found across the construction industry, thus limiting the diffusion of this type of performance assessment from the research domain into practice.

Whilst the building envelope design is based on Australian practice, research outcomes and conclusions have scientific international relevance, and design considerations apply to several international contexts.

Supplementary Materials: The following are available online at https://www.mdpi.com/article/ 10.3390/buildings11060261/s1, Figure S1: Mass Timber Wall Variants, Figure S2 Timber-framed wall variants.

Author Contributions: Conceptualization, A.B. and E.G.; methodology, A.B. and E.G.; software, A.B.; validation, A.B.; formal analysis, A.B. and E.G.; investigation, A.B. and E.G.; writing-review and editing, A.B. and E.G. All authors have read and agreed to the published version of the manuscript.

Funding: This research was conducted as a part of CRC-P50578 in conjunction with LendLease and DesignMake. The CRC Programme supports industry-led collaboration between industry, researchers and the community.

Institutional Review Board Statement: Not applicable. 
Informed Consent Statement: Not applicable.

Conflicts of Interest: The authors declare no conflict of interest. The funders had no role in the design of the study; in the collection, analyses, or interpretation of data; in the writing of the manuscript, or in the decision to publish the results.

\section{References}

1. Klepeis, N.E.; Nelson, W.C.; Ott, W.R.; Robinson, J.P.; Tsang, A.M.; Switzer, P.; Behar, J.V.; Hern, S.C.; Engelmann, W.H. The national human activity pattern survey (NHAPS): A resource for assessing exposure to environmental pollutants. J. Expo. Sci. Environ. Epidemiol. 2001, 11, 231-252. [CrossRef]

2. International Organization for Standardization Geneva. Hygrothermal Performance of Building Com-Ponents and Building ElementsAssessment of Moisture Transfer by Numerical Simulation; BSI: London, UK, 2007.

3. Crook, B.; Burton, N.C. Indoor moulds, sick building syndrome and building related illness. Fungal Biol. Rev. 2010, 24, 106-113. [CrossRef]

4. Lu, C.; Deng, Q.; Li, Y.; Sundell, J.; Norbäck, D. Outdoor air pollution, meteorological conditions and indoor factors in dwellings in relation to sick building syndrome (SBS) among adults in China. Sci. Total Environ. 2016, 560-561, 186-196. [CrossRef] [PubMed]

5. Dewsbury, M.; Law, T.; Potgieter, J.; Fitz-Gerald, D.; McComish, B.; Chandler, T.; Soudan, A. Scoping Study of Condensation in Residential Buildings: Final Report; Australian Building Codes Board, Department of Industry Innovation and Science: Hobart, Australia, 2016.

6. Australian Building Code Board. Building Code of Australia 2013: National Construction Code Series Volume 1; Australian Building Codes Board: Canberra, Australian, 2013.

7. Allsopp, D.; Seal, K.J.; Gaylarde, C.C. Introduction to Biodeterioration; Cambridge University Press: Cambridge, UK, 2004.

8. Verdier, T.; Coutand, M.; Bertron, A.; Roques, C. A review of indoor microbial growth across building materials and sampling and analysis methods. Build. Environ. 2014, 80, 136-149. [CrossRef]

9. Gutarowska, B.; Piotrowska, M. Methods of mycological analysis in buildings. Build. Environ. 2007, 42, 1843-1850. [CrossRef]

10. Sedlbauer, K.; Krus, M.; Breuer, K. Biohygrothermal method for the prediction of mould growth: Procedure and health aspects. In Proceedings of the Healthy Building, Proceedings of the ISIAQ Conference, Singapore, 7-11 December 2003; National University of Singapore: Singapore, 2003; pp. 666-672.

11. Australian Institute of Health and Welfare. Chronic Respiratory Diseases in Australia: Their Prevalence, Consequences and Prevention. Available online: https:/ / www.aihw.gov.au/reports/chronic-respiratory-conditions/chronic-respiratory-diseasesaustralia/contents/table-of-contents (accessed on 27 April 2021).

12. Kraus, M. Airtightness as a key factor of sick building syndrome (SBS). In Proceedings of the International Multidisciplinary Scientific GeoConference: SGEM: Surveying Geology \& Mining Ecology Management, Albena, Bulgaria, 30 June-6 July 2016; pp. 439-445.

13. Gobakken, L.R.; Lebow, P.K. Modelling mould growth on coated modified and unmodified wood substrates exposed out-doors. Wood Sci. Technol. 2010, 44, 315-333. [CrossRef]

14. Sedlbauer, K. Prediction of mould growth by hygrothermal calculation. J. Therm. Envel. Build. Sci. 2002, 25, 321-336. [CrossRef]

15. Vereecken, E.; Roels, S. Review of mould prediction models and their influence on mould risk evaluation. Build. Environ. 2012, 51, 296-310. [CrossRef]

16. Gradeci, K.; Labonnote, N.; Time, B.; Köhler, J. Mould growth criteria and design avoidance approaches in wood-based materials-A systematic review. Constr. Build. Mater. 2017, 150, 77-88. [CrossRef]

17. Brambilla, A.; Sangiorgio, A. Mould growth in energy efficient buildings: Causes, health implications and strategies to mitigate the risk. Renew. Sustain. Energy Rev. 2020, 132, 110093. [CrossRef]

18. Gradeci, K.; Labonnote, N.; Time, B.; Köhler, J. A probabilistic-based approach for predicting mould growth in timber building envelopes: Comparison of three mould models. Energy Procedia 2017, 132, 393-398. [CrossRef]

19. Spiegel, R.; Meadows, D. Green Building Materials: A Guide to Product Selection and Specification; John Wiley \& Sons: Hoboken, NJ, USA, 2010.

20. England, P.; Iskra, B. Australian building code change-Eight-storey timber buildings. In Proceedings of the International Scientific Conference on Woods \& Fire Safety; Springer: Cham, Germany, 2020; pp. 219-225.

21. Kremer, P.D.; Symmons, M. Mass timber construction as an alternative to concrete and steel in the Australia building industry: A PESTEL evaluation of the potential. Int. Wood Prod. J. 2015, 6, 138-147. [CrossRef]

22. Kremer, P.; Fahy, P.; Zaman, A. Understanding the risk and reward in the adoption of mass timber construction in Australia. Mass Timber Constr. J. 2019, 2, 15-20.

23. Brambilla, A.; Gasparri, E. Hygrothermal behaviour of emerging timber-based envelope technologies in Australia: A preliminary investigation on condensation and mould growth risk. J. Clean. Prod. 2020, 276, 124129. [CrossRef]

24. Sedlbauer, K.; Krus, M. A new model for mould prediction and its application in practice. In Proceedings of the International Conference on Buldign Physics, Leuven, Belgium, 14-18 September 2003.

25. Hukka, A.; Viitanen, H.A. A mathematical model of mould growth on wooden material. Wood Sci. Technol. 1999, 33, 475-485. [CrossRef] 
26. ASHRAE Standard 160-2016. Criteria for Moisture-Control Design Analysis in Buildings; ASHRAE: Atlanta, GA, USA, 2016.

27. Lepage, R.; Glass, S.V.; Knowles, W.; Mukhopadhyaya, P. Biodeterioration models for building materials: Critical review. J. Arch. Eng. 2019, 25, 04019021. [CrossRef]

28. Manfred Kehrer, O. WUFI (Wärme and Feuchte Instationär)-Oak Ridge National Laboratory (ORNL)/Fraunhofer IBP Oak Ridge National Laboratory, Computer Software. Available online: https://www.osti.gov//servlets/purl/1231793 (accessed on 20 May 2014).

29. Delgado, J.M.; Barreira, E.; Ramos, N.M.; de Freitas, V.P. Hygrothermal Numerical Simulation Tools Applied to Building Physics; Springer Science \& Business Media: Berlin, Germany, 2012.

30. Glass, S.; Zelinka, S. Moisture relations and physical properties of wood. In Wood Handbook-Wood as an Engineering Material; General Technical Report FPL-GTR-282; Department of Agriculture: Madison, WI, USA; Forest Service: Madison, WI, USA; Forest Products La-boratory: Madison, WI, USA, 2010; 22p.

31. Kordziel, S.; Glass, S.V.; Boardman, C.R.; Munson, R.A.; Zelinka, S.L.; Pei, S.; Tabares-Velasco, P.C. Hygrothermal characterization and modeling of cross-laminated timber in the building envelope. Build. Environ. 2020, 177, 106866. [CrossRef]

32. Glass, S.V. Hygrothermal Analysis of Wood-Frame Wall Assemblies in a Mixed-Humid Climate; Research Paper, FPL-RP-675; Department of Agriculture: Madison, WI, USA; Forest Service: Madison, WI, USA; Forest Products Laboratory: Madison, WI, USA, 2013; 27p.

33. Kang, Y.; Kim, S. Evaluation of the hygrothermal performance by wall layer component of wooden houses using WUFI sim-ulation program. J. Korean Wood Sci. Technol. 2016, 44, 75-84. [CrossRef]

34. Cho, H.M.; Wi, S.; Chang, S.J.; Kim, S. Hygrothermal properties analysis of cross-laminated timber wall with internal and external insulation systems. J. Clean. Prod. 2019, 231, 1353-1363. [CrossRef]

35. Boardman, C.R.; Glass, S.V. Improving the accuracy of a hygrothermal model for wood-frame walls: A cold-climate study. Buildings 2020, 10, 236. [CrossRef]

36. Remund, J.; Kunz, S. Meteonorm: Global Meteorological Database for Solar Energy and Applied Climatology; Meteotest: Bern, Switzerland, 1997.

37. Gasparri, E.; Brambilla, A.; Aitchison, M. Hygorthermal analysis of timber-based external walls across different Australian climate zones. In Proceedings of the WCTE 2018, World Conference on Timber Engineering, Seoul, Korea, $20-23$ August 2018.

38. Pihelo, P.; Kalamees, T. The effect of thermal transmittance of building envelope and material selection of wind barrier on moisture safety of timber frame exterior wall. J. Build. Eng. 2016, 6, 29-38. [CrossRef]

39. Sadovský, Z.; Koronthályová, O. Exploration of probabilistic mould growth assessment. Appl. Math. Model. 2017, 42, 566-575. [CrossRef]

40. Gradeci, K.; Labonnote, N.; Time, B.; Köhler, J. A probabilistic-based methodology for predicting mould growth in façade constructions. Build. Environ. 2018, 128, 33-45. [CrossRef] 